\title{
Repeat expansion in spinocerebellar ataxia type 17 alleles of the TATA-box binding protein gene: an evolutionary approach
}

Jürgen Tomiuk, Lutz Bachmann, Claudia Bauer, Arndt Rolfs, Ludger Schöls, Christian Roos, Hans Zischler, Mathias M Schuler, Silke Bruntner, Olaf Riess and Peter Bauer

European Journal of Human Genetics (2008) 16, 661; doi:10.1038/sj.ejhg.5201997

Correction to: European Journal of Human Genetics doi:10.1038/sj.ejhg.5201721; published online 11 October 2006.

Since the above publication, Dr Schöls has noticed that his affiliation information is incorrect. The correct affiliation should have been:
Ludger Schöls

Department of Neurology and Hertie-Institute for Clinical Brain Research, University of Tübingen, Tübingen, Germany. 